\title{
The Composition Dependence Selectivity Changes by Plasticizer at the Cation Sensors Based on Tetracycline Antibiotics
}

\author{
Jonggy Baek, Jin-San Kim, Insook Rhee Paeng, and Ki-Jung Paeng \\ Department of Chemistry and Medical Chemistry, Yonsei Lnversitw, Honju 220-710, Korea. E-mail: paengkanonseiackr \\ Department of Chemistry, Seoul Homen's Lniversitv, Seoul 139-774, Korea \\ Received August 1, 2007
}

\begin{abstract}
The performances of tetracycline based cation selective polymeric membrane electrodes of many sets with different plasticizers were investigated as the selectivity of ion-selective electrodes and optodes are greatly influenced by membrane solvent and also controlled by plasticizers. The membrane 1 with Bis(2-ethylhexyl) sebacate (DOS) and additive shows good potentiometric performance toward $\mathrm{Ca}^{-}$(slope: $27.8 \mathrm{mV}$ per decade: DL: -4.52 ) including selectivity. Contrastingly, membrane + with Dibutyl phthalate (DBP) shows nearNernstian response. it has also shown the best measuring range and detection limit for $\mathrm{Ca}^{2+}(29.5 \mathrm{mV}$ and

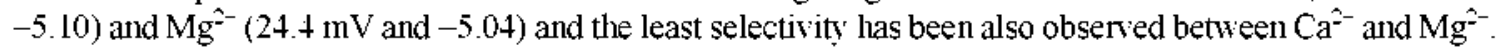
When the membrane 1 and + were used together to flow șistem, we could determine the concentration of $\mathrm{Ca}^{2-}$ and $\mathrm{Mg}^{2+}$. simultaneously.
\end{abstract}

Key Words : Cation selective electrodes, Tetracycline. Plasticizer, Membrane

\section{Introduction}

The development of electrochemical sensor for direct monitoring of key ions in various matrices is a rapid growing avenue of analytical chemistry. ' Now-a-day's the carrier based ion selective electrodes (ISEs) are one of the most important groups of chemical sensors. and a PVC-based membrane electrode is a typical example: it is readily prepared by small amount of electroactive compound. (ionophore and lipophilic salts) into solvent polymeric matrix and plasticizer. ${ }^{23}$ Each components have the role for developing successful sensors and the selectivity is mostly relied on the molecular recognition ability of ionophores.

The metal binding antibiotics are very attractive choice as cation selective ionophores and have many examples. ${ }^{4-6}$ The tetracyclines (TCs) could be very good candidate since they showed great affinity towards $\mathrm{Ca}^{2+}$ and $\mathrm{Mg}^{2+}$. ${ }^{+}$Recently. however. our group reported that the $\mathrm{TC}$ based membrane electrode formulated with common PVC composite exhibits response toward $\mathrm{Ca}^{2+}$ but not for $\mathrm{Mg}^{2-}$. Thus we investigated the reactivity between $\mathrm{TC}$ and $\mathrm{Mg}^{2+}$ to confirm binding of them even in the solution and electrode membrane. With spectroscopic data. we concluded that $\mathrm{TC}$ and $\mathrm{Mg}^{2+}$ could be very well bound together in solution. but it might be interfered by the mobility of $\mathrm{Mg}^{2-}$ ion in membrane. In the artificial membrane environment. plasticizers with high dielectric constant should improve the preference of $\mathrm{Mg}^{2-}$ compared to $\mathrm{Ca}^{2+}$. since $\mathrm{Ca}^{2+}$ tends to form more voluminous ion-ligand complex stoichiometry and its larger radius. ${ }^{10.1]}$ Thus we prepared many set of membrane electrodes with different plasticizers, and also described the membrane composition dependent selectivity changes toward $\mathrm{Mg}^{2+}$ ion

\section{Experimental}

Reagents and Apparatus. The tetracycline (TC) used in this work was purchased from Sigma (Saint Louis. Mo). Poly(vinyl chloride) (PVC), various plasticizers viz Bis(2ethylhexyl) sebacate (DOS). 2-Nitrophenyl octyl ether (oNPOE) and Dibutyl phthalate (DBP), and potassium tetrakis (4-cllorophenyl borate) (KTpCIPB) were supplied from Fluka (Ronkonkoma. NY). All other chemicals including nitrate salts of examined cations and solvents were analytical reagent grade and used without further purification. Standard solutions and buffers were prepared with the use of de-ionized water.

UV-Vis spectra were obtained using Perkin Elmer UV-Vis spectrophotometer (LX20-000B) and NMR spectra were obtained using Bruker 400 NMR spectrometer with DMSOdo as a solvent.

Preparation and Evaluation of Polymer Membranes and Electrodes. PVC matrix membranes were prepared

Table 1. The compositions of polymer membrane electrodes based on tetracycline

\begin{tabular}{cccccc}
\hline Composition & Ionophore & Matrix & Plasticizer & lipophilic additive & intemal filling solution \\
\hline membrane l & TC $(6 \mathrm{mg})$ & PVC $(66 \mathrm{mg})$ & DOS $(125.30 \mathrm{mg})$ & KTpCIPB lo0\% & $10^{-3} \mathrm{M} \mathrm{KCl}$ \\
membrane 2 & TC $(6 \mathrm{mg})$ & PVC $(66 \mathrm{mg})$ & DOS $(128 \mathrm{mg})$ & $\times$ & $10^{-3} \mathrm{M} \mathrm{KCl}$ \\
membrane 3 & TC $(6 \mathrm{mg})$ & PVC $(66 \mathrm{mg})$ & o-NPOE $(125.30 \mathrm{mg})$ & KTpCIPB lo0\% & $10^{-3} \mathrm{M} \mathrm{KCl}$ \\
membrane 4 & TC $(6 \mathrm{mg})$ & PVC $(66 \mathrm{mg})$ & DBP $(125.30 \mathrm{mg})$ & KTpCPB lo0\% & $10^{-3} \mathrm{M} \mathrm{KCl}$ \\
\hline
\end{tabular}




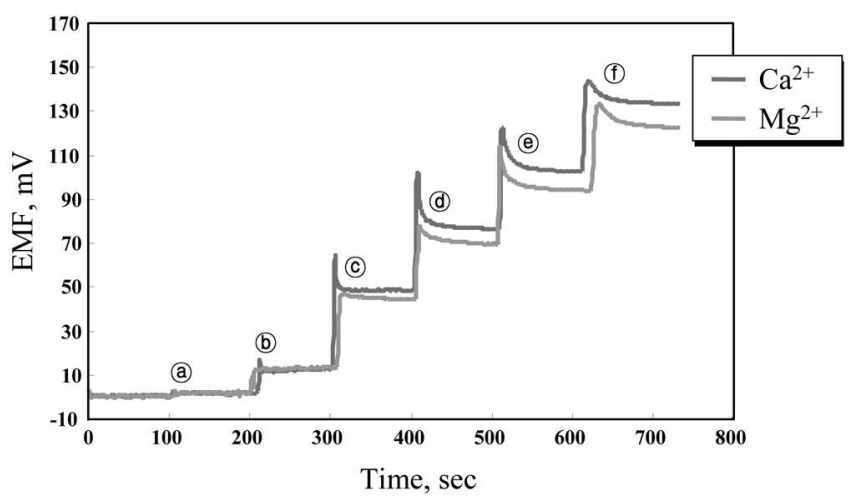

Figure 1. Dynamic response curves of the optimized ISE using tetracvcline for step changes in concentration of $\mathrm{CaCl}_{2}$ and $\mathrm{MgCl}_{2}$; a) $1.0 \times 10^{-5} \mathrm{M}$, b) $1.0 \times 10^{-5} \mathrm{M}$, c) $1.0 \times 10^{-1} \mathrm{M}$, d) $1.0 \times 10^{-3} \mathrm{M}$, e) $\left.1.0 \times 10^{-2} \mathrm{M}, \mathrm{t}\right) 1.0 \times 10^{-1} \mathrm{M}$.

according to the method reported previously. ${ }^{12}$ The mixture of ionophore, PVC and plasticizer with total weight of 200 mg was dissolved in $1 \mathrm{~mL}$ THF. The solution was cured to produce an elastic membrane. A small disk of $5.5 \mathrm{~mm}$ diameter was cut out from the resulting PVC membranes and then mounted into the electrode bodies (IS-561: Glasblaserei Möller. Zürich, Switzerland). The specific membrane compositions are sumntarized in Table 1

The potentionetric behavior of the menibrane electrodes were evaluated with conventional ISE configuration. Selectivity coefficients were estimated according to the separate solution method at an interfering cation concentration of 0.1 $M{ }^{13}$ The detection limit and slope of the membrane electrodes were obtained from the calibration plots (Fig. 1) using the reconminended procedure. ${ }^{1+}$

\section{Results and Discussion}

Many researchers have reported very high affuity of TC toward $\mathrm{Ca}^{3+}$ and $\mathrm{Mg}^{2-}$. 7.15 We found that both of $\mathrm{Ca}^{2-}$ and $\mathrm{Mg}^{-}$shows very good reactivity to $\mathrm{TC}$ and it was checked with UV-Vis spectrophotometer (data not shown here) and $\mathrm{C}^{13}$-NMR (Fig. 2). Fron UV-Vis spectra, we confirmed that the $\mathrm{TC}$ and $\mathrm{Mg}^{2-}$ is very well bound together as $1: 1$ ratio in solution like $\mathrm{Ca}^{2+}$. From $\mathrm{C}^{13}-\mathrm{NMR}$, we found the bonding sites of $\mathrm{TC}$ with $\mathrm{Mg}^{3+}$ are $-\mathrm{OH}$ attached to $\mathrm{Cl}$ and $\mathrm{Cl} 2$. which is different than biological system $(\mathrm{Cll}$ and $\mathrm{Cl} 2 \mathrm{in}$ biosystem) ${ }^{16}$ The proposed stereo structure of $\mathrm{Mg}^{3+}$ bound TC is shown in Figure 3. With spectroscopic data. we concluded that $\mathrm{TC}$ and $\mathrm{Mg}^{2+}$ could be very well bound together in solution. but it might be interfered by the mobility of $\mathrm{Mg}^{2+}$ ion in membrane.

The basic PVC membrane electrodes (membrane 1 and 2 in Table 1) incorporating TC were prepared and its potentiometric perfomances as cation selective electrodes were reported in our previous work. ${ }^{9}$ According to those data. the PVC electrode based on TC exhibits a good Nernstian response $(26.6 \mathrm{mV} / \mathrm{dec})$ for calcium ion $\left(\mathrm{Ca}^{3+}\right)$ and a comparable responses toward various divalent cations except $\mathrm{Mg}^{2}$. In the artificial membrane environment. plasticizers

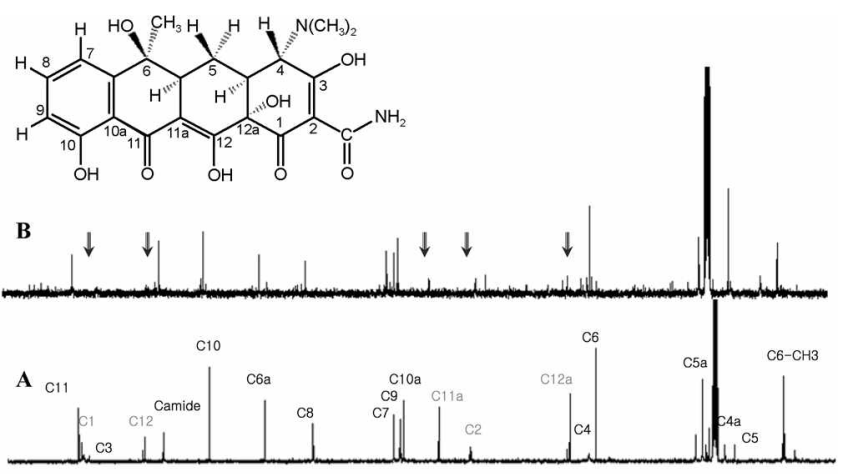

$20019018017016015014013012011010090 \quad 8070 \quad 6050 \quad 40 \quad 30 \quad \mathrm{ppm}$ Figure 2. $\mathrm{C}^{13}-\mathrm{NMR}$ spectra of $\mathrm{TC}(\mathrm{A})$ and $\mathrm{TC}^{-}-\mathrm{Mg}^{2+}(\mathrm{B})$.

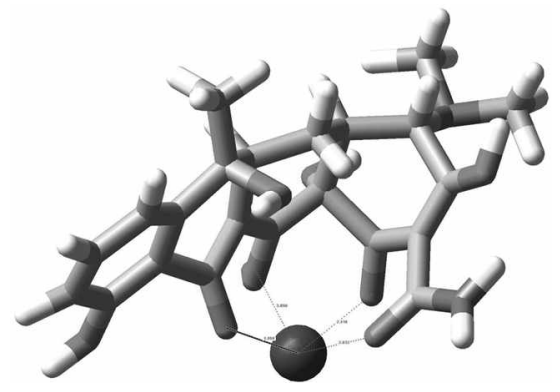

Figure 3. Proposed stereo views of the structure of TC with $\mathrm{Mg}^{2-}$ from NMR.

with high dielectric constant should improve the preference of $\mathrm{Mg}^{2-}$ compared to $\mathrm{Ca}^{2-}$, since $\mathrm{Ca}^{2-}$ tends to form more voluminous ion-ligand complex stoichiometry and its larger radius. ${ }^{3,13,11}$ Based on previous reports. no clear cut rule can account for all the selectivity of $\mathrm{Mg}^{2+}$ over $\mathrm{Ca}^{2-}$ by membrane compositions. such as plasticizers. and thus we prepared many set of membrane electrodes with different plasticizers. The potentiometric perfomances of the membrane electrodes examined in this experiments (listed in Table 1) are summarized in Table 2. As shown in Table 2. both of membrane 1 and 2 show very good responses to $\mathrm{Ca}^{2-}$ and membrane electrode with lipophilic additive has better over all performance than without additives as $\mathrm{Ca}^{2+}$ ion sensor. Addition of additive gives more response to $\mathrm{Mg}^{3+}$ too, because it increases the mobility of cations to membrane

The selectivity of solvent based polymeric membrane has determined by the difference between the standard free

Table 2. The Slope and detection limit in the calibration curves for $\mathrm{Ca}^{2-}$ and $\mathrm{Mg}^{2-}$ ions by membrane electrodes based on tetracycline and their selectivity

\begin{tabular}{|c|c|c|c|c|c|}
\hline & \multicolumn{2}{|l|}{$\mathrm{Ca}^{2-}$} & \multicolumn{2}{|c|}{$\mathrm{Mg}_{\mathrm{g}}{ }^{1+}$} & \multirow[b]{2}{*}{$\log K_{C a^{2-}}^{q^{p h o t}}$} \\
\hline & $\begin{array}{c}\text { Slope } \\
\left(\text { mVdecade }^{-1}\right)\end{array}$ & $\begin{array}{c}\mathrm{DL} \\
\log [\mathrm{M}]\end{array}$ & Slope & DL & \\
\hline Membrane 1 & 27.8 & -4.52 & 15.1 & -2.95 & -1.80 \\
\hline Membrane 2 & 23.8 & -3.77 & 6.6 & -2.00 & -2.34 \\
\hline Membrate 3 & 16.1 & -4.80 & 15.1 & -3.92 & -0.77 \\
\hline Metnhratle 4 & 29.5 & -5.10 & 24.4 & -5.04 & -0.54 \\
\hline
\end{tabular}




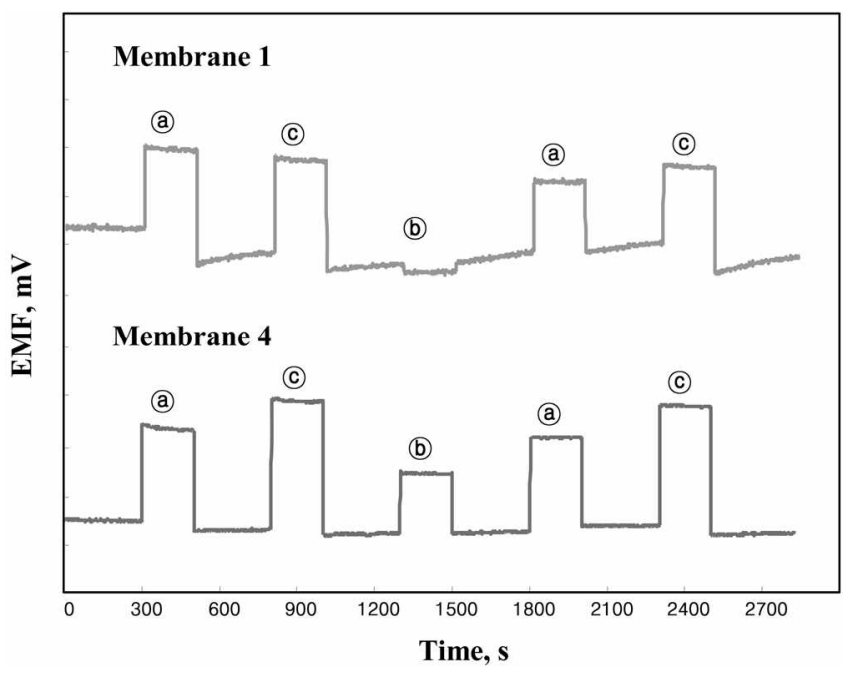

Figure 4 . The potentiometric responses of membrane 1 and 4 for $\mathrm{Ca}^{2+}, \mathrm{Mg}^{2-}$ and mixture in the successive flow system. (a) $\mathrm{Ca}^{2+}$ only, $\mathrm{Mg}^{2+}$ only, $\mathrm{Ca}^{2+}$ and $\mathrm{Mg}^{2-}$ misture.

energies of the ions in the aqueous and organic phases. which can be influenced by the plasticizers. Carrier based ISEs are also strongly influenced by the membrane solvent. It has been assumed that this influence is due to the polarity of plasticizer, which can be estimated from the given dielectric constant. Among the many plasticizers we examined. three plasticizers viz DOS. $o$-NPOE and DBP have been chosen. because DOS, 0 -NPOE and DBP have the order of increasing lipophilicity. As indicated in Table 2, mentbrane 4 with DBP shows near-Nernstian response it has also shown the best measuring range and detection linit for $\mathrm{Ca}^{2-}$ (slope: $29.5 \mathrm{mV}$ per decade: $\mathrm{DL}:-5.10)$ and $\mathrm{Mg}^{3+}(24.4 \mathrm{mV}$ and $-5.04)$ and the least selectivity has also been observed between $\mathrm{Ca}^{2+}$ and $\mathrm{Mg}^{2+}$. Contrastingly. membrane 1 with DOS and additive shows good potentiometric perfornance toward $\mathrm{Ca}^{2+}(27.8 \mathrm{mV} ;-4.52)$ including selectivity. The membrane 3 with $o$-NPOE shows very poor performances to both of $\mathrm{Ca}^{3-}$ and $\mathrm{Mg}^{2-}$. The potentiometric performances and selectivity could be related to three factors: Firstly. the dielectric constant of membrane. secondly the structural difference of plasticizer and finally. association of ion-pair. The more lipophilic plasticizers are less selective towards $\mathrm{Mg}^{2-}$ compared to $\mathrm{Ca}^{2+}$. Thus we night control the selectivity between two divalent cations. The ISE performance of membrane electrode could be related to association of ion- pair. because complexation might be prevented in the polarity and sterical effect of membrane. However. the association between divalent metal ion and ligand is not prevented in DBP based membrane. Thus we need further studies of complexation properties of metal cations and TC in solvent.

We investigated the usage of the membrane 1 and 4 together to flow system for simultaneous determination of the concentration of $\mathrm{Ca}^{3+}$ and $\mathrm{Mg}^{2-}$. The results were depicted in Figure 4. Solution of $\mathrm{Ca}^{2+} \cdot\left(\mathrm{Ca}^{2-}+\mathrm{Mg}^{2+}\right) . \mathrm{Mg}^{2+}$, $\mathrm{Ca}^{2+}$ and $\left(\mathrm{Ca}^{2+}+\mathrm{Mg}^{2}\right)$ were applied successively into the both ISEs through flow system. As shown in Figure 4. we can deternine the concentration of $\mathrm{Ca}^{2+}$ by ISE with membrane 1 without interference from $\mathrm{Mg}^{2-}$. We can estimate the $\mathrm{Mg}^{2-}$ by subtracting $\mathrm{Ca}^{2+}$ concentration from the mixture. obtained from ISE using Membrane 4. In this way, it shows the possibility of measuring both ions simultaneously in the mixture by ISEs with same ionophores.

\section{References}

1. Cattrall, R. W. In Ion-Selective Electrode Rev: Petgamon Press: New York, 1984.

2. Bakker. E.: Buhlmann, P, Pretsch, E. Chem Rev 1997. 97. 3083.

3. Buhlmann. P.: Pretsch. E.: Bakker. E. Chent. Rev 1998. 98.1593.

4. Morf. W. E.: Simon. W. Heh: Chim . Acta 1971. 54.2683,

5. Schater. M.: Sheldrick. G. M.: Bahner. I.: Lackner. H. Angew: Chem. Iht 1998, 37.2391.

6. Paeng. I. R. And. Sci. Tech. 2005, 18. 491

7. Wessels, J. M:Ford, W. E.: Szymezak. W: Schnider. S. J. Phys. Chen. $B$ 1998. 102.9323.

8. Scholz. O.: Schubert. P.: Kintrup. M:: Hillent. W. Biochemistry 2000. 39. 10914.

9. Baek. J.; Rhee, I.: Paeng. K.-J. J. Kor Electrochem. Soc. 2006.9. 132 .

10. Spichiger. U. E. Electroanalysis 1993. 5.739.

11. Eugster. R.: Rosatzin. T:: Rusterholz. B.: Aebersold. B.: Pedrazza. U.: Ruegg. D.: Schmid. A.: Spichiger. U. E.: Simonl. W. Anol. Chint Acta 1994. 289. 1

12. Park. S. S.: Jung. S. O.; Kim. S. M.: Kım, J.-S. Bull. Kor: Chem. Soc. $1996,17,405$.

13. Umezawa Y.; Umezawa, K.: Sato. H. Pure Appl. Chem 1995, 67. 507.

14. Kimura. K.: Yajima. S.: Tatsumi. K.: Yokoyama. M.: Oue. M Anal. Chem. 2000. 72. 5290.

15. Schneider. S.: Schmıtt, M. O; Brehm. G.: Reıher, M.: Matousek. P.; Towre. M. Photochem. Photobiol. Sci. 2003, 2. 1107.

16. Palm, O. J.: Dalm, D.: Mettew: N.; Profit, J.: Hinrichs. W. w'w'hastlab. dest de science ammal report 2005 report. 